\title{
O PENSAMENTO INACABADO DO ENSAIO ${ }^{1}$
}

\author{
Joseph Bonenfant
}

Tradução: Glória Carneiro do Amaral

Interrompo a leitura do diário de Ramuz, do qual tiro algumas notas para esboçar uma reflexão sobre a forma do ensaio criada e praticada por Montaigne e que poderíamos chamar de ensaio livre ${ }^{2} .24$ de junho de 1910: "A inspiração: Mergulho no próprio eu". 2 de agosto de 1912: "Só há um trabalho, é o do próprio eu". 27 de julho de 1908: "O amor do geral e o desprazer do abstrato. Conciliar eslas duas coisas." 24 de agosto de 1908: "Vejo claramente meu instinto: fazer poesia com análise. Mais do que nunca, vejo agora o poder e a beleza das idéias simples. Não me deixarei engajar." Qualquer uma destas frases poderia ser colocada em paralelo com um pensamento de Montaigne, atravessando os séculos. Num e noutro caso, a mesma preponderância da pessoa do autor sobre a idéia abstrata, mesmos lances do espírito instantâneo, mesmo prazer do pensamento vagabundo e aberto. Mas o diário de Ramuz libera um pensamento mais fragmentado, uma reflexão mais inacabada do que os Essais de Montaigne. O diário recusa títulos e temas. É necessário observar as diferenças circunstanciais que envolvem estas reflexōes. Montaigne aciona sua fantasia para comentar os textos antigos, ultrapassando assim a tradição dos florilégios, enquanto que Ramuz registra suas reflexōes quotidianas. A citação de início ou de apoio no primeiro tem a mesma função da data no segundo: ser o objeto, o lugar e a matéria de uma reflexão; o escritor imprime al sua marca particular,

1 Originalmente publicado em Études Litteraires, avril, 1972.

2 Livre, por oposição ao ensaio erudito ou sistemático que desenvolve um argumento e se quer persuasivo. Encontraremos observaçð̌es esclarecedoras sobre as diferentes formas de ensaio em Elements of the Essay de Scholes e Klaus, New York, Oxford University Press, 1969 bem como em Robert Champigny, Pour une esthétique de l'essrai, Paris, Leltres Modernes, Minard, 1967, Situation, $n^{\mathrm{Q}} 15$. 
aprofundando assim um momento do texto ou do tempo. O pensamento que toma forma ao longo da experiencia de um e de outro é, ele próprio, um momento de reflexăo contingente, ligado ao instante da leitura ou da duração. Fragmento de tempo, o instante é fugidio como um pensamento, ele próprio fragmento do pensamento. Nada melhor do que esta aproximaçăo para fazer sentir o caráter fragmentário do pensamento do ensaio, em sua forma, substancia e circunstanclas. Este aspecto típico do caráter inacabado do pensamento livre coloca o problema da unidade na diversidade, da totalidade na fragmentação, da continuidade de sentido ao longo das rupturas pelas quais lhe convém passar.

$\mathrm{Na}$ sua meditação escrita, o ensaísta revela sempre, em diferentes graus, o desejo de retratar. Propõe sua própria contingência como ponto de partida, sua própria diversidade como inspiração e seu ato de escrever como ato primeiro de pensamento. Mas como isto não é fácill Todo pensamento tende a se estabelecer habitualmente a um nível de generalidade que possa lhe conferir um caráter universal. O movimento das idéias se limita, então, previamente, a uma ordem sistemática e aceita o recurso da abstração. É o que se encontra nos pensamentos filosóficos tradicionais, justamente chamados de sistemáticos. A habilidade consiste em eliminar tudo que é particular e sobretudo circunstanclas de tempo, espaço e pessoa. A unidade de um assunto pode assim ser demonstrada graças ao encadeamento das idéias e à sua progressão linear e até tornar-se uma aventura fascinante. Convenhamos que esta atividade abstrata é capaz de revelar aspectos importantes do que chamamos, em geral, a verdade. As contingencias apresentam-se livres de seus aspectos momentâneos e grosseiros, e possibilitam a inteligibilidade. Ou seja, um discurso filosófico sobre as paixões pode valer para todos os homens, pelo seu caráter abstrato e suas qualidades universais e ser útil. Salientemos a pretensảo ao didatismo inerente a este tipo de discurso demonstrativo e que é sua única justificativa. A verdade se impóe pela sua dimensão, amplitude e pureza. Ela emana de um discurso que elimina aquele que o faz. Não é forçoso que, em larga medida, ela permaneça, por um justo retorno, indiferente àquele que o recebe? Poderfamos dizer que o mesmo está no mesmo? E todos os gostos não existem na natureza?

Criando este gênero de ensalo, Montaigne inverteu o valor abstrato da verdade. Na prática e voluntariamente, ele falou de si mesmo e das coisas colocando-se no centro de seus escritos. Ele năo somente escreveu o que pensava de tudo. É com ele que se pode afirmar que escrever tornou-se o meio e o ato do pensamento. Ele se viu, sem tergiversações, contingente e diverso, náo recuou diante de sua "condição baixa", arriscando-se a nada encontrar nela de universal. Apresentou-se a si próprio em pensamento e em escritura, propos sua própria desordem, suas próprias inconstâncias e suas próprias mutações, sem preocupar-se com a imperfeiçăo de sua imagem. Os Essais săo uma tentativa de 
realizaçâo pessoal. Montaigne se toma como assunto de conhecimento; busca a fórmula concreta da sabedoria.

O pensamento racional sempre leva a melhor diante da subjetividade, pois ela discorre a partir dos princípios do próprio objetivismo por ele professado. Talvez ele tenha uma justa noção do julgamento concreto, mas prefere o julgamento abstrato. Como $o$ idealismo julgaria o comportamento humano? Conhecemos a posição de Montaigne: "O que fazer com estes ṕlncaros elevados da filosofia sobre os quais nenhum ser humano pode repousar e estas regras que excedem nosso uso e nossa força?". A modéstia é a primeira qualidade de Montaigne. Ele escreve ainda: "Não podemos nos manter além das nossa forças e dos nossos meios." É uma modéstia lúcida. É a clarividência de Montaigne que the dá o sentimento de suas próprias forças, o senso de medida e a revelação de sua capacidade. Confere um caráter de generalidade a estas duas frases, mas trata-se dele mesmo. Nós o reconhecemos como assunto da frase ou do pensamento. Se estas afirmativas podem deixar subentender a vaidade, ele tempera esta audácia com outra frase de generalização: "O homem é um sujeito maravilhosamente vão, diverso e cambiante". A pretensão, ou a falsa modéstia, seria justamente colocar o "eu" pessoal no lugar do "homem" impessoal. Não se trata de desencanto, mas noção exata da consciência de si próprio. Seria facilmente demonstrável que a objetividade de Montaigne não é da ordem da idéia, mas da generalização própria da afirmação sentenciosa. É uma questão de estilo. "Os píncaros elevados da filosofia" remetem, em sua idéia, ao idealismo? Nada é mais duvidoso. Mas é certo que ele não gosta das palavras abstratas. Ele suspeita do conhecimento teórico, satiriza os sistemas filosóficos sua barafunda ao longo da história do pensamento. Limita, portanto, as pretensões do conhecimento, reconduzindo-o para o terreno da observação e da verificação; exercita-se no conhecimento de si próprio sem impaciência nem pretensão, sem nunca perder de vista a realidade de suas paixões e de seu temperamento. Desconfia também da razão e de suas falsas razões. Analisa-se mais do que se imagina. No entanto, convenhamos, trata-se de uma tarefa de sabedoria. Conhecimento e sabedoria são, para ele, vias empiricas; não se convertem em objetivo, mas são um procedimento; não um ideal, mas um ponto de partida. $O$ julgamento concreto, forçosamente subje tivo, satisfaz-se com o limitado e com o contingente.

Voltando ao caráter fragmentário do ensaio, que também encontramos no diário e na correspondencia, é preciso dizer que não é de se lamentar que seja assim. Não se deve ver no Inacabado de uma reflexão uma falta de perfeição, nem no fragmentário um sinonimo de truncado. Infeririamos daf uma qualidade ou integridade do conhecimento impossiveis, só desejáveis. Da mesma forma como não poderíamos fazer a soma de mil verdades parciais para 
corrigir a falha de cada uma através de sua inserção no conjunto todo. $O$ problema que levanto aqui tem dois aspectos. No seu inverso, $o$ inacabado remete ao tempo. A fonte de fragmentaçáo do saber é que tudo que se diz tem o caráter fugidio do instante. Que este caráter seja igualmente frágil e único faz compreender que o conhecimento concreto tem sempre necessidade de assegurar sua posição na experiencia e que a cintilação de sua expressão, também concreta, precisa ser colocada à prova, senão é o inútil reflexo do instante passageiro. No seu reverso, é o problema mesmo da escritura. Escrever, afirma-se, é pensar. Deve-se acrescentar: é pensar no instante. Se o pensamento é circular, a escritura é linear. Costuma-se dizer que a entrevista revela o que uma pessoa realmente pensa. A simples palavra transposta em escritura permanece palavra: reflete um pensamento sinuoso e repetitivo. Só a escritura permite a escolha e o verdadeiro pensamento. Através da escritura, o pensamento tem tempo de refletir, de dividir, de ligar, de se organizar. Ela se desdobra numa linha de instantes que se unem numa frase temporal e todas as possibilidades do sentido vêm dar.

Escrever apresenta-se como dar sentido a instantes que por si só não o apresentam, é ligar fragmentos que se precipitam de forma incoerente numa duração cega. A escritura é o espaço de expectativa do sentido e o que acontece nesta expectativa é um pensamento. Lamentar que um pensamento seja fragmentário é deplorar que tudo não se escreva ao mesmo tempo, que todo sentido não jorre de um só jato. É o ensaio que permite recuperar estas noções fundamentais. É da própria natureza do ensaio mover-se no inacabado. Mas não existe gennero literário que não tenha relação, em virtude do ato instantâneo de escrever, com o esboço e a formação de um' pensamento. Quantas máximas não poderfamos tirar das obras dramáticas, romanescas, poéticas? E. Lablénie fez um Montaigne auteur des maximes ${ }^{3}$ Empreitada fácil. Poder-se-ia fazer o mesmo a partir da obra de Racine, de Flaubert e de Aragon. Com todos os escritores de peso. A primeira razão é certamente que o escritor procura generalizar as verdades que encontra e conferir-lhes um caráter sentencioso que seja, ao mesmo tempo, uma condensação do sentido e uma emanação das circunstancias. Mas como negar que sobretudo estas verdades gerais sejam testemunhos da rica fecundidade do instante criador, a recompensa que a escritura dá para a expectativa paciente? Espontâneas, sinceras, por vezes fantasiosas, estas verdades momentaneas não se oferecem com a evidencia da certeza? Fragmentárias, elas o são como o instante; inacabadas, elas se dão pelo que valem. Mas como ele, elas são vivas, surpreendentes. Enriquecem-se pelas próprias condições. Brotam de 
uma espontaneidade, atenta ou negligente, que pode produzir o efeito de uma desordem. O problema da desordem do pensamento decorre naturalmente de seus aspectos fragmentários.

A crítica sempre teve tendencia a procurar nos Essais de Montaigne uma ordem oculta na desordem. Dar a abundância de estudos temáticos. Mas isto não muda nada; cada um dos ensaios de Montaigne é temático. Ele dá um título a cada um dos textos. Confessa, no entanto, que nem sempre o título corresponde ao tema tratado. E mesmo que houvesse perfeita correspondência, o problema continuaria. O título ajuda o leitor a ler melhor, a seguir os "saltos e cambalhotas" de um pensamento vagabundo. Deve-se recusar esta liberdade de postura quando se busca, através do tema, captar a unidade profunda, a ordem oculta? Esquecem-se sobretudo as leis próprias de uma escritura, os procedimentos da associação e o surgimento das imagens. Não se encontrando esta ordem, deplora-se a falta de inteligibilidade global. Montaigne optou deliberadamente pela liberdade evanescente de seu ser e das coisas para construir o discurso habitual dos homens, aparentemente incoerente. Trata com igual seriedade o principal e o acessório. Segue com divertida fidelidade o processo de seu pensamento, sem dissociar seu tema das circunstâncias que o levaram a tratar dele. Diverte-se ao se ver pensando; deixa-se comover pelo gesto da sua mão escrevendo. Nada faz para remediar esta desordem; avoluma-a até, ao indića-la, e ratifica-a como uma prova do sucesso de sua intenção. Prefere uma desordem verdadeira a uma falsa ordem que nasceria de uma "ordenação lógica". Não se preocupa em definir o sentido de um escrito, sem acreditar que um sentido possa ser definitivo. Contenta-se em persegui-lo livremente, arriscando-se a não encontrá-lo, sem contenção nem ordem premeditada.

Assim seu texto conserva sempre uma forma aberla que se presta às adiçōes e não deixa nunca a impressão de se fechar sobre si mesmo. Não o ameaça o que se poderia chamar de totalidade fechada, sujeita à interpretação. É um texto sem resumo possível, como toda grande obra de criação, sem centro fixo, no fim da qual o autor brandiria, depois de longos desvios e de todas as agruras do estilo regular e da composição rigorosa, a idéia da qual ele partira e em torno da qual se movimentara. Montaigne náo se sacrifica nunca à preocupação com a unidade, nem recorre a esta totalidade circular e a uma ordem estabelecida de antemão. É necessário, segundo a expressão de Jean-Yves Pouilloux, que a leitura de Montaigne "constitua a desordem do texto 
como seu objeto" e "como elemento de uma produção literária e filosófica" ${ }^{4}$ É preciso chegar até al para captar a forma praticada por Montaigne e por todos os que, depois dele, tomaram-na por modelo, sem nunca superá-la. O que seria, aliás, um pensamento ordenado e constrangido que pretendesse estar sempre à espreita das coisas e exprimir o olhar instantaneo sobre si e sobre o mundo? Seria uma contradição nos termos. Um tal pensamento se fecharia sobre seu próprio funcionamento e se comprazeria nos rigores de uma forma que ele julgaria definitiva. Ora, Montaigne não recuou nunca diante da desordem confessa de seus textos, enriquecendo-os ou acrescentando-lhe impenitentes sutilezas.

Estes acréscimos são, ao mesmo tempo, a aceitação da desordem e a manutenção do inacabado. O essencial não muda, a substância permanece a mesma, mas a forma desenvolve outros arabescos. Simples preocupação de estilo? Se quisermos. Já é louvável. Mas a desordem permanece imutável, o pensamento não repudia nunca sua vagabundagem curiosa. Os acréscimos refletem instantes que se encadeiam a instantes anteriores. A escritura do pensamento segue a linha caprichosa de instantes sucessivos, recuperados através dos anos. Há aí a consciência de uma insuficiência e como que a certeza de que os remanejamentos, possíveis uma ou duas vezes, deixarão um dia de sê-lo. A atividade corretora é a própria confissāo da falta radical de tempo. Como o pensamento, o instante deixará um dia de seguir espontaneamente. A morte selará a desordem dos pensamentos que pertenceram a momentos fugidios, mas para sempre cintilantes, nunca perdidos, sempre encontrados no segundo pensamento da leitura, nos mil pensamentos novos da leitura sempre inacabada de Montaigne

\section{Universidade de Sherbrooke}

4 J.-Y POUHL.IOUX. Lire les "essais" de Montaigne, Paris, François Maspero, 1969, p. 41 e p 60. Ler este excelente estudo que contém coisas novas e, em seguida, as, mais volumosos, de $P$. Villey, M. Butor, E. I sblénie, M. Baraz e Hugo Friedrich. 